\title{
Marc Quaghebeur (dir.), Les sagas dans les littératures francophones et lusophones au XXe siècle
}

\author{
Jean-Paul De Nola
}

\section{(2) OpenEdition}

\section{Journals}

Édition électronique

URL : http://journals.openedition.org/studifrancesi/638

DOI : 10.4000/studifrancesi.638

ISSN : 2427-5856

Éditeur

Rosenberg \& Sellier

\section{Édition imprimée}

Date de publication : 1 avril 2015

Pagination : 199-200

ISSN : 0039-2944

\section{Référence électronique}

Jean-Paul De Nola, « Marc Quaghebeur (dir.), Les sagas dans les littératures francophones et lusophones au xxe siècle », Studi Francesi [En ligne], 175 (LIX | I) | 2015, mis en ligne le 01 avril 2015, consulté le 18 septembre 2020. URL : http://journals.openedition.org/studifrancesi/638 ; DOI : https://doi.org/ 10.4000/studifrancesi.638

Ce document a été généré automatiquement le 18 septembre 2020.

\section{(c) (i)}

Studi Francesi è distribuita con Licenza Creative Commons Attribuzione - Non commerciale - Non opere derivate 4.0 Internazionale. 


\title{
Marc Quaghebeur (dir.), Les sagas dans les littératures francophones et lusophones au $\mathrm{XX}^{e}$ siècle
}

\author{
Jean-Paul De Nola
}

\section{RÉFÉRENCE}

MARC QUAGHEBEUR (dir.), Les sagas dans les littératures francophones et lusophones au XX⿳亠口冋口灬 siècle, Bruxelles, Peter Lang, 2013, «Archives et Musée de la Littérature», pp. 384.

1 La plupart des collaborateurs à cet ouvrage collectif proposent une définition de la saga stricto sensu pour examiner ensuite dans quelle mesure l'œuvre de leur choix se conforme à cette définition ou bien s'en écarte. Une synthèse de ces définitions pourrait être celle-ci: la saga est une œuvre narrative en prose, anonyme ou collective, qui implique l'histoire d'une famille s'étendant sur trois ou quatre générations au minimum. La saga n'est ni un roman historique, ni un roman familial. Ce genre fut cultivé en Scandinavie, plus précisément en Islande, du XII au XIV siècle. La saga peut trouver des équivalences dans les autres littératures et à des époques différentes: Niebelungen, romanceros espagnols, chansons de geste françaises, poésies anglosaxonnes, pour arriver, à l'aube du xxe siècle, à The Forsyte Saga (1906-1929) de John Galsworthy. Par analogie on a commencé à parler de la «saga des Kennedy», famille riche et brillante, poursuivie par un destin tragique. Par des analogies de moins en moins justifiées, le mot saga a été galvaudé à propos de romans-feuilletons, films et séries télévisées, et le moindre "soap-opera" a pris des allures d'épopée scandinave (voir André Huet, Il était une fois la saga, les médias et nous, op. cit., pp. 21-46). Il sera plus intéressant de décider quelles sont les œuvres des littératures françaises - au pluriel qui pourraient, d'une manière ou d'une autre, présenter une parenté, même partielle, avec la saga lato sensu. 
2 La France ne figure pas dans ce panorama. Mais y figure la judéité francographe: Albert Cohen est un écrivain de premier ordre, entré dès 1993 dans la collection de la Pléiade. Les quatre volumes de sa Geste des Juifs (1930-1969) sont considérés par la critique comme une saga dans l'acception moderne du terme: l'histoire de la famille Solal à travers plusieurs générations. Cette geste antisémite conçue par un Juif, certainement en guise de parodie de l'antisémitisme, évoquerait «un mode légendaire de transcendance du réel». C'est la thèse de Joseph BRAUN dans sa minutieuse et un peu prolixe monographie de cinquante pages: Si c'est une saga... L'œuvre romanesque d'Albert Cohen (pp. 137-186). Ressassement ou fantômes d'une saga juive de la troisième génération par Bernadette DESORBAY (pp. 187-206): dans les Graffitis de Chambord (2008) d'Olivia Elkaim revivent trois générations de la famille Rosenwicz, éliminée à Auschwitz, à l'exception du petit-fils Trevor qui, célibataire, laissera s'éteindre la lignée. Il s'agit d'une «saga minimale qui s'inscrit dans la tradition juive» (p. 205). Troisième œuvre d'un Israélite, de nationalité belge cette fois-ci: c'est Philippe Blasband, qui nous est présenté par Michel VOITURIER (Le livre des Rabinovitch, une saga chorale, pp. 207-212). Il s'agit d'une galerie de treize portraits imaginaires, représentant une même famille entre 1920 et 1980.

3 Avec Blasband nous avons rejoint le territoire de la Belgique romane. Élise MAснот (De la saga à l'écriture du mythe personnel, pp. 71-81) aborde Le Régiment noir (1972) d'Henry Bauchau. Le genre «sagæsque» (déplaisant néologisme) est impliqué dans la mesure où l'histoire d'une famille (celle de l'auteur) s'entrelace avec l'Histoire (la Guerre de Sécession) et avec l'élément épique: la sécession (séparation entre parents) se reflète dans la Sécession (entre États américains). Le cycle du "Prince d'Olzheim" de Pierre Nothomb (Marc QUAGHEBEUR, pp. 83-107), ambitieux et complexe, comporte cinq volumes (1944-1960). Selon l'exégète: «Cela dessine les traits d'une saga quasiment métaphysique à partir de l'historial et de l'historique» (p. 86). La petite principauté d'Olzheim est imaginaire, elle se situerait à l'intérieur du territoire du Luxembourg grand-ducal. L'histoire d'une famille (histoire non autobiographique, mais autoréférentielle) épouse la grande Histoire (en partie fictionnelle), qui débouche sur le rêve du baron Nothomb (rêve qui fut aussi très fortement caressé par le rexiste Léon Degrelle): la reconstitution de l'entité lotharingienne, royaume d'Entre-Deux. Le Prince d'Olzheim serait-ce, grâce à «la multiplication des péripéties narratives et (à) l'étalement temporel» (p. 105), une manière de saga historico-métaphysique? Michel оттеN présente (pp. 109-115) "Meurtres" (1919-1941) de Charles Plisnier, saga et roman familial. Cette œuvre en cinq volumes constituerait donc, selon notre critique, une sorte de saga, puisqu'il s'agit d'une vie de saint - façon de parler! - qui est aussi la vie héroïque d'un subversif, mû par son idéal communiste. C'est aussi une histoire de la famille Annequin, s'étendant sur plusieurs générations. Troisième présence de la Belgique francophone: Pierre Mertens et le détournement de la saga par Marie-France RENARD (pp. 337-346). Selon celle-ci les trois volumes regroupés sous le titre Paysage avec la chute d'Icare (2009), posséderaient les principales caractéristiques de la saga, sans oublier la référence au mythe. Mais le romancier lui-même repousse cette interprétation en affirmant que sa trilogie est une anti-saga. Il ne serait pas logique de le contredire, à moins de suggérer que la saga pour lui est un ancien amour, dont il se serait dépris...

Quelles sagas en Suisse romande? se demande Yves BRIDEL (pp. 307-311). Partant de la constatation que la Confédération Helvétique, heureux pays, n'a pas d'Histoire - quand vous avez nommé la pomme de Guillaume Tell, vous avez dit tout -, on pourrait en 
conclure: pas de sagas. Mais Yves Bridel se donne tout de même la peine d'examiner scrupuleusement des ouvrages qui pourraient présenter certaines analogies, non décisives, avec la saga.

5 Place au Québec! Catherine PONT-HUBERT en parle, À propos de Michel Tremblay (pp. 59-69) et de son cycle montréalais Chroniques du Plateau Mont-Royal, où le joual, argot de Montréal-Est, francophone (car il existe aussi un Montréal-Ouest, à prépondérance anglophone), où le joual donc n'est pas interdit de séjour. Catherine Pont-Hubert considère ces Chroniques de Tremblay comme une véritable saga, même si en l'occurrence elle est dépourvue de «transcendance historique». Dans L'Indien oublié: " $L a$ Saga des Béothuks" de Bernard Assiniwi, écrivain cri du Québec (pp. 269-283), Peter KLAUS nous révèle l'existence de la minorité aborigène dans la Belle Province et, minorité dans la minorité - ou "Tiers oublié» - les francophones parmi ces Amérindiens. Dans La Saga des Béothuks (1996), livre à mi-chemin entre le roman historique et l'essai ethnologique, l'écrivain amérindien francographe raconte l'histoire d'une tribu, éteinte depuis 1829, de l'île de Terre-Neuve: les Béothuks. La Saga des Béothuks proclame un statut autodéfini par son auteur.

De la lointaine Haïti nous provient "Mère-Solitude" d'Émile Ollivier (par François HOFFMANN, pp. 49-57). CEuvre (1983) qui, en tant qu'«histoire d'une famille à travers plusieurs générations» pourrait bien correspondre à l'acception moderne du genre "sagæsque".

7 Selon Yves CHEMLA, auteur des pages sur "Origines" d'Amin Maalouf, une affaire de famille (pp. 117-126), le texte qu'il a choisi (2004) pour représenter le Liban est conforme à la définition de la saga: «il s'agit bien des brassages sur trois générations, dont certains moments frôlent l'épopée, représentée ici par la résistance à l'adversité et aux forces contrariantes, et qui sont corrélés aux soubresauts de l'Histoire» (p. 117). L'histoire familiale des Maaloufs, chrétiens maronites, s'entrelace avec l'Histoire de la Montagne libanaise.

8 Pour le Maghreb Chloé MONEY propose Une saga en forme de polygone: l'odyssée de Kateb Yacine (pp. 241-252). L'histoire de la famille de Kateb, sur plusieurs générations, est accrochée à l'Histoire de la guerre d'Algérie, de 1945 à 1966: c'est trop peu pour une saga.

9 Quant à l'Afrique noire, Silvia RIVA y consacre ses pages sur Sagas et transmission héréditaire. Hexagrammes peuls chez Amadou Hampâté Bâ et Tierno Monénembo (pp. 285-303). Il s'agit de deux écrivains subsahariens d'expression française, d'ethnie "peule" tous les deux. Au premier, Malien, on doit deux volumes de Mémoires (1993-1996), qui ne semblent pas adhérer à «la démarche chorale et sérielle, typique de la saga» (p. 288). Le second, Guinéen, a publié un roman, Peuls (2004), qui «s'autodéfinit en tant que saga» (p. 293). En effet, nous y trouvons une série d'histoires, pas une trame unique; de nombreux parents isomorphes et un long étalement temporel: $\mathrm{du} \mathrm{xv}^{\mathrm{e}}$ siècle à 1896 (début de la colonisation française). Au Congo ex-belge nous rencontrons d'abord "Tu le leur diras" de Clémentine M. Falk-Nzuji (voir l'article de Maurice AMURI MPALA-LUTEBELE, pp. 215-239). Nous pourrions bien avoir affaire ici à une vraie saga (publiée en 2005), puisqu'elle narre les vicissitudes d'un clan familial s'étendant sur quatre générations et s'entremêlant avec l'histoire de la colonisation belge, puis avec celle de la République Démocratique du Congo. Un autre congolais, Jean-Claude KANGAMBA, se demande "Deux vies, un temps nouveau" de Ngombo Mbala, première saga 
congolaise? (pp. 313-325). L'œuvre en question, en douze chapitres (1973) embrasse quatre générations. Mais l'intrigue ne se déroule qu'en un seul tome de deux cents pages, tandis que le traitement des personnages est plutôt "minimaliste", le commentateur l'admet. Quant à Nabile FARÈs (Écrivain ou griot, à propos d'un genre nouveau: L'épopée négative, pp. 347-351), on a l'impression que ce collaborateur n'a pas traité clairement le sujet imposé par les organisateurs.

Il reste trois contributions sur les lettres lusitaniennes, qu'elles proviennent du Portugal, de l'Angola ou du Brésil. Et restent encore, en guise de conclusion, les savantes Propositions pour une esthétique sagcesque (pp. 355-375) par Christophe MEURÉE. Il y aurait des équivalences entre l'esthétique de la saga et certaines formes de la littérature moderne ( $\mathrm{XIX}^{\mathrm{e}}$ siècle) et postmoderne ( $\mathrm{xx}^{\mathrm{e}}$ et $\mathrm{xxI}^{\mathrm{e}}$ siècles), caractérisées par le retour des personnages: cycles romanesques (Balzac, Zola), romans-fleuves (Martin du Gard, Duhamel, Romains), littérature post-exotique (la «Shaggå» d'Antoine Volodine) et d'autres Nouveaux Romans. 